\title{
Promoting Intercultural Competence in EFL Classroom
}

\author{
LI Xiao-mei \\ South China Business College, Guangdong University of Foreign Studies, Guangzhou, China
}

\begin{abstract}
Promoting intercultural competence is an important objective in foreign language education. The main purpose of the study was to examine the effects of incorporating "noticing, comparing, reflecting, and interacting” teaching model in English-as-a-foreign-language (EFL) classroom. Data were collected from students' reflective writing reports and semi-structured interviews. The analysis of the data revealed that this teaching practice could serve as an effective tool to develop students' intercultural competence, particularly regarding intercultural knowledge, attitudes, and awareness.
\end{abstract}

Keywords: intercultural competence, College English, teaching model

\section{Introduction}

Globalization, fast-developing technology, and migration in this era have contributed to the great importance of intercultural competence. In other words, learning and understanding other cultures has become an important objective in second or foreign language education (Liu, 2016; Su, 2011). This is due to the fact that "intercultural competence does not happen automatically when people from different nations meet under the same institutional context. Even when there are not obvious conflicts, that does not mean that there is successful interaction" (Hiller, 2010, p. 50). Just as Byram (2011) indicates "language teaching should prepare learners as worldcitizens instead of global human capital” (p. 29). Under this move, teaching practice concerning how to promote intercultural competence has gained considerable concern in different levels of schools in English language teaching in China, especially in tertiary institutions, where English is considered as an essential part of higher education and a required course for undergraduate students. According to the latest guidelines of College English Curriculum, which was issued in 2016 by Ministry of Education of the People's Republic of China, cultivating intercultural communication should be regarded as a clear objective of College English teaching and learning, aiming to develop learners' abilities to use English as a tool to effectively communicate and interact with people from diverse cultural backgrounds.

Acknowledgements: This research is sponsored by Guangdong provincial project A Study of Intercultural College English Teaching Based on Constructivism Under the Background of the Belt and Road (B\&R), 2017; by the university project College English Teaching Model Based on Intercultural Perspective (SCBC) (Grant No. 2018JG27), and by the university project An Action Research of the College English Teaching Model Based on Intercultural Perspective Under the Background of B\&R (SCBC) (Grant No. 2017JG03). This research is also sponsored by the university project Research on the Development of College Students' Cross-Cultural Pragmatic Competence: Based on the "Reading-Writing Integration" Teaching Mode (Grant No. 2018JG08).

LI Xiao-mei, MA degree, lecturer, South China Business College, Guangdong University of Foreign Studies, Guangzhou, China. 
However, intercultural competence is a definitely complex aspect of foreign language education, including its definition and teaching implementation (Moeller \& Osborn, 2014). Borghtetti (2013) puts forward three-phase teaching block for nurturing students' intercultural competence to language teachers, suggesting cognitive and affective processes are the basis, which will lead to the development of intercultural awareness and skills. Different from Borghtetti's proposal, Liddicoat and Scarino (2013) define intercultural teaching and learning as "a cycle of interconnected processes in which the learner engages in experiences of languages, cultures and their relationship” (p. 59). They further explain that the cycle covers four processes: noticing, comparing, reflecting, and interacting, which does not have a fixed starting point. That is to say, the question regarding how to effectively develop learners' intercultural competence during the course of language teaching remains open and disputable.

The present study makes an attempt to explore how to promote students' intercultural competence in English-as-a-foreign-language (EFL) classroom by incorporating "noticing, comparing, reflecting, and interacting” teaching model (Liddicoat \& Scarino, 2013).

\section{Literature Review}

A comprehensive model of intercultural competence is put forward by Byram (1997), which has firmly rooted in intercultural teaching and learning. His model covers four key areas, including attitudes, knowledge, skills, and critical cultural awareness. Deardorff (2006), who based on views from 23 prominent intercultural experts, concludes intercultural competence is "the ability to communicate effectively and appropriately in intercultural situations based on one's intercultural knowledge, skills and attitudes” (p. 13). Similarly, Fantini (2007) defines knowledge, attitudes, skills, awareness as well as language proficiency as essential elements of intercultural competence. In spite of some differences among the models and definitions, most researchers generally agree that knowledge, attitudes, skills, and awareness are crucial components of intercultural competence.

Realizing the importance of connecting language with cultures, great efforts have been made to nurture students' intercultural competence in second language education. A case study by Polisca (2011) showed that the project of V-PAL (Virtual-Partnerships for All Languages), a computer-mediated language scheme could be effective in raising students' intercultural awareness and interaction. Some studies (Byon, 2007; Su, 2011) implemented a cultural portfolio project to enhance students' cross-cultural competence, which allowed students to create their interest-based cultural hypotheses, then to affirm or reject their hypotheses through investigation and interaction. A study (Kiss \& Weninger, 2017) demonstrated that diverse visual components could serve as useful resources for developing students' intercultural awareness and knowledge in educational settings. An interview-based study (Liu, 2016) illustrated that an intercultural extracurricular activity (home-foreign) student contacts on campus could effectively facilitate students to heighten their intercultural awareness and communicative competence. However, due to the lack of authentic environments for foreign language use in many universities, the most common and important form for students to acquire intercultural knowledge and foster intercultural competence is foreign language classes (Liu, 2016). Therefore, the purpose of the study is to explore the effects of "noticing, comparing, reflection, interaction” teaching sequences for promoting students' intercultural competence in EFL classroom. In particular, the study addressed the following questions. 
(1) Do English learners gain development in intercultural competence by employing "noticing, comparing, reflection, interaction" teaching model?

(2) What are learners’ perceptions of applying “noticing, comparing, reflection, interaction” teaching model in EFL classroom?

\section{Participants}

Participants of this study are 40 EFL learners, majoring in Finance from an average university in the east of China. They are 18-19 years old, involving 28 females and 12 males, who are taught by the research of this study. Based on participants' self-reports, they have received formal English teaching for about 10 years, with intermediate level in English proficiency. Since English learning and teaching is still considered as an essential part of high education, most non-English majors are also required to take "College English", which is an integrated English course for the first two years in the universities, followed with ESP (English-for-Special-Purpose) courses later. The objective of integrated English course is to further enhance students' language abilities in listening, speaking, reading, and writing, as well as to promote their intercultural competence.

\section{Teaching Intervention}

In designing and carrying out "noticing, comparing, reflection, interaction” teaching model, the research took Liddicoat and Scarino’s (2013) teaching principles into serious account and followed the detailed guidelines. According to Liddicaot and Scarino, noticing is a fundamental activity that will stimulate students to examine something new and attempt to understand what it is under the teachers' guidance. The process of comparing can inspire students to compare and contrast their home culture and other cultures. The act of reflection enables students to understand the new linguistic and cultural knowledge. Interaction provides students opportunities to negotiate meanings and understand diverse cultural phenomena from different perspectives. Considering the fact that students generally have limited knowledge about western cultures, the author of this study usually considered "noticing” as the starting point for a new topic or unit.

The teaching interventions were generally carried out with the following stages. Stage 1 , the teacher incorporated something interesting or special to engage students' attention, guiding them to focus on the new topic arising from the text. Examples of activities in this stage were a segment of English movie about parenting relevant to target cultures, or some typical pictures about classroom learning in English-speaking countries. Stage 2 , the teacher guided students to read the texts thoroughly as well as to comprehend the specific culture factsarising from the texts. At this stage, thought-inspiring questions were raised and a certain amount of exercise were designed to guide students to make connections with their existing knowledge and experiences, and stimulated them to compare and contrast home culture with the target culture. For example, they were asked to describe the differences and similarities of college life between some English-speaking countries and China. Stage 3, one or two critical incident exercises related to intercultural aspects (Snow, 2015) were offered to students to reflect what they have learned and interact with others. Afterwards, they were encouraged to discuss the possible explanations for those critical incident exercises in small groups and finally report their ideas after small group discussion and interaction. 


\section{Instruments}

Various instruments can serve as effective tools to assess intercultural competence, such as questionnaires, interactive activities in small groups, oral and written reports (Fantini, 2009). Thus, this classroom-based research focused on the following aspects as the sources of the data: students' reflective writing reports and interviews.

\section{Data Collection and Analysis}

The teaching intervention lasted one semester, with 18 weeks in total. The students were asked to write and submit a reflective writing report when a unit came to an end. There were eight units in the textbook, with topic ranging from college life to friendships. Thus, students were required to submit a writing report every two weeks. The reflective writing report mainly covered three types questions: (1) use their words to describe one specific cultural aspect arising from the relevant unit, (2) compare and contrast the similarities and differences of the relevant cultural aspect, (3) open questions such as their perceptions, beliefs, and doubts about cultures. At the end of the semester, a total of 310 reflective writing reports were collected.

In addition, a semi-structured interview, involving a series of planned questions, was conducted to elicit student's thoughts, feelings, attitudes, or experiences related to the application of "noticing, comparing, reflection, interaction" teaching model in the course. Six students were divided into three pairs and each pair was interviewed for half an hour in Chinese. The interviews were audio-recorded with the consent of the interviewees.

The author based on content analysis (McDonough \& McDonough, 1997) to analyze and code the reflective writing reports and interviews. The writing reports and coded excerpts were respectively read with great care before they were categorized and given different themes.

\section{Findings}

\section{Development of Intercultural Competence: Knowledge}

The rich data of the reflective writing reports outline that such teaching intervention can be effective in developing students' cultural and intercultural knowledge. Most of them were able to describe the topics that covered in the courses with some details, sometimes although there were some linguistic and grammatic mistakes in the reports, indicating they have gained some understanding and insights into the target language cultures, such as social values, lifestyles, parenting, and education. The following excerpts show the evidence of gaining development in cultural knowledge.

“After learning this unit, I know that many English-speaking countries like USA, England and Canada value privacy very much. Asking about one’s age and salary is generally considered as impolite.”

"Now, I know that the foundation of friendship is quite different across cultures. To my surprise, friends in some west countries don't expect too much concrete help from each other, such as spontaneously lending some money to a friend who has financial problems, offering a job to their friends. It seems that they pay more attention to emotional support.”

\section{Development of Intercultural Competence: Attitudes}

One striking feature of the reflective writing reports revealed that most participants developed positive attitudes towards intercultural learning. Some students expressed their curiosity and willingness to probe into 
deep understanding about some specific aspects of target language cultures. Some students clearly displayed their openness about cultural differences across nations. Certain students described their eagerness to take a trip or live in some English-speaking countries for a short time to experience the real-life cultural diversity, especially food, climate, social customs, and so on. Such descriptions evidenced their positive attitudes towards target language cultures as well as language learning. The following excerpts are typical examples of this type of reports.

"I have learned that American young people are very independent and self-reliant and they are expected to live independently when they reach 18 years old. How can their parents guide them to be independent individual from a very young age? I am eager to know more about this way of parenting because I want to be a better parent in the future.”

"Different from the society I am living, it seems that the majority of young people in Britain, American and Canada generally don't live with their parents, especially after they start their own family. However, it is common and widely accepted for Chinese young couples to live with parents, even grandparents together. I think, both lifestyles have their benefits and problems, and they are reasonable are practical for people living in different social backgrounds.”

\section{Development of Intercultural Competence: Awareness}

The reflective writing reports also demonstrated that certain students gained deeper understandings of some cultural issues relevant to English-speaking countries through comparison, contrast, reflection, or critical analysis. Two participants reported their intercultural awareness as follows.

“American people value privacy and freedom a lot. Take my foreign teacher, Ben, a man from American for example. He always stresses that we should make an appoint in advance if we want to drop in his house. I think he also values privacy and freedom a lot. If we visit him suddenly, his personal schedule may be destroyed. No wonder he often tells us to make an appoint before we pay a visit to him.”

"I used to think college students in many English-speaking countries live a very relaxed life. Now, I have realized that actually, they also have a lot of assignments, such as writing thesis, group work project, exams and so on. In fact, they are also under great pressure. They also need to work study to get a degree.”

\section{Interviews}

Overall, six participants involved in the interviews expressed positive perceptions towards the application of "noticing, comparing, reflection, interaction" teaching model. All of them commented that they have gained more knowledge about some cultural practices of some English-speaking countries. Five of them noted that this teaching model was helpful for them to understand other cultures step by step. They also agreed that they were motivated to dig deeper into some aspects of the cultural issues with teacher's guidance. The following excerpts are typical examples of such beliefs:

"I was deeply impressed by those segments of the video which were showed in our English class. And I attempted to understand those cultural practices. Cases we analyzed in the classroom were very meaningful. I think those cases have helped me better understand how to interact with people from other countries. I want to read more cases other interacting with people across cultures.”

“This teaching model have benefited me a lot. I have gained more insights into other cultures. I have known more cultural facts.There are so many foreigners living in Guangzhou, I might interact with them some day or occasionally. I think I will respect other cultures and try to communicate with them with appropriate manners or ways. Those cases we discussed in the class were very inspiring." 
On the other hand, certain interviewees felt that it was quite challenging for them to make comparisons about different cultures since they didn't have very deep understanding about those topics or couldn't get access to the resources they needed. In addition, they indicated that the constraints of English proficiency also hindered the flow of ideas, just as they stated "I racked my brain trying to express what I wanted to write or say in English, but sometimes I still couldn't come up with a right word or a sentence. Sometimes I felt very distressed”. Two students complained that they had no idea about what they should compare for some cultural topics, suggesting that teachers should provide more tips about comparison. One participant noticed that English have been applied to international communication settings and pointed out "we had better understand other cultures, just learning western cultures is far from satisfactory".

\section{Discussion and Conclusion}

The current study examined the effects of applying "noticing, comparing, reflection, interaction" teaching model in EFL classroom in an average university from China. As can be noted, the findings appeared to be positive. Based on the reflective writing reports, the majority of students who took part in this study gained some progress in the development of intercultural competence, including intercultural knowledge, attitudes as well as awareness. The findings suggested that this teaching practice can serve as a useful tool to arouse students' curiosity and willingness for cultural learning, motivating them to relate the new knowledge to their own cultural background and construct something new through comparison, reflection, and interaction during the process of English language acquisition. At the same time, the findings showed that this teaching practice has helped them understand the dynamic nature of the western cultures and realize the significance of connecting language with cultures.

The data of the interviews confirmed that most participants agreed that "noticing, comparing, reflection, interaction” teaching model could serve as a useful tool to develop their intercultural knowledge as well as awareness, reflecting the positive effects of this teaching practice. They stated that they were provided lots of opportunities to engage actively and socially through cultural dialogues when they interacted with classmates or teacher, revealing their learning process involved the five principles of intercultural language learning, including constructing knowledge, making connections, interaction, reflection as well as responsibility (Liddicoat \& Scarino, 2013). Moreover, some participants claimed that the task of writing reflective reports inspired them to think critically and write their understanding with a critical mind. The comments raised by the participants suggest that teacher should provide more scaffolding to the students, for example, providing some writing samples and offering some specific guidelines about how to make comparisons and identify similarities.

The study is limited in that only a small number of students involved this project. In addition, the researcher just regarded the reflective writing reports and interviews as the sources of the data. Apart from these sources, other data such as notes of discussion in classroom, students' oral speeches, and the interaction in English classrooms also can provide more evidence for the research questions.

\section{References}

Borghetti, C. (2013). Integrating intercultural and communicative objectives in the foreign language class: A proposal for the integration of two models. Language Learning Journal, 41(3), 254-267. 
Byon, A. S. (2007). The use of cultural portfolio project in Korean culture classroom: Evaluating stereotypes and enhancing cross-cultural awareness. Language, Culture, and Curriculum, 20, 1-19.

Byram, M. (1997). Teaching and assessing intercultural communicative competence. Bristol, PA: Multilingual Matters Ltd.

Byram, M. (2011). A research agenda for “intercultural competence.” In A. Witte and T. Harden (Eds.), Intercultural competence: Concepts, challenges, evaluations (pp. 19-35). Bern, Switzerland: Peter Lang.

Deardorff, D. K. (2006). Identification and assessment of intercultural competence as a studentoutcome of internationalization. Journal of Studies in International Education, 10(3), 241-266.

Fantini, A. E. (2007). Exploring and assessing intercultural competence: Research report. St. Louis, MO: Centre for Social Development, Washington University.

Fantini, A. (2009). Assessing intercultural competence: Issues and tools. In D. K. Deardorff (Ed.), The SAGE handbook of intercultural competence (pp. 456-476). Thousand Oaks: Sage.

Hiller, G. G. (2010). Innovative methods for promoting and assessing interculturalcompetence in higher education. In Proceedings of the Center for Educational Resources in Culture, Language, and Literacy: Intercultural Competence Conference. Retrieved September 28, 2014, from http://cercll.arizona.edu/_media/development/conferences/2010_icc/moloney_harbon

Kiss, T., \& Weninger, C. (2017). Cultural learning in the EFL classroom: The role of visuals. ELT Journal, 71(2), 186-196.

Liddicoat, A. J., \&Scarino, A. (2013). Intercultural language teaching and learning. Chichester: John Wiley \& Sons.

Liu, L. K. (2016). Exploring intercultural competence through an intercultural extracurricular activity in Taiwan. Journal of Language and Cultural Education, 4(1), 99-109.

McDonough, J., \& McDonough, S. (1997). Research methods for English language teachers. London: Arnold.

Moeller, A. J., \& Osborn, S. R. F. (2014). A pragmatist perspective on building intercultural communicative competency: From theory to classroom practice. Foreign Language Annals, 47(4), 669-683.

Polisca, E. (2011). Language learning and the raising of cultural awareness through internet telephony: A case study. The Language Learning Journal, 39(3), 329-343.

Snow, D. (2015). English teaching, intercultural competence, and critical incident exercises. Language \& Intercultural Communication, 15(2), 285-299.

Su, Y. (2011). Promoting intercultural understanding and reducing stereotypes: Incorporating the cultural portfolio project into Taiwan's EFL college classes. Educational Studies, 37(1), 73-88. 